\title{
Anatomy of a Community-Level Fiscal Impact Model: FIT-4-NH
}

Tracey L. Farrigan, John M. Halstead, Martin L. Shields, Douglas E. Morris, and Edmund F. Jansen, Jr.*

\begin{abstract}
This paper describes the development of a fiscal impact tool for New Hampshire communities (FIT-4-NH). FIT-4-NH belongs to a family of computergenerated fiscal impact assessment models designed to estimate the impacts to local government revenues and expenditures that result from economic changes. In the past, work in this area has centered on the completion of countylevel models for the midwestern states. FIT-4-NH is unique in that it was designed for rural community-level use in the northern New England region of the country.
\end{abstract}

\section{INTRODUCTION}

Rural communities have always been concerned with the fiscal and public service impacts of various economic shocks, such as the introduction of a new firm. In the past two decades, economists have responded to this concern with a variety of fiscal impact models. These computer-generated models were designed to analyze a wide range of public sector effects of economically related transformations, and recently have become both more prevalent and user-friendly. The mainframe computer-based models of the 1980 s have given way to microcomputerbased models available to practitioners in many parts of the country (Halstead, Leistritz, and Johnson 1991). Unfortunately, many of these tools are generic and/or aggregated and are therefore misleading when applied to diverse rural areas. For instance, earlier models were typically developed for relatively large states, mainly in the Midwest. They were also based on county-level units of analysis and used a gravity component for estimation of labor force relationships, which is acceptable for states like Iowa and Nebraska where the natural landscapes are virtually featureless planes (Swenson and Eathington 2000). Therefore, they are not very reliable prototypes for modeling efforts in smaller states with smaller populations, different geographic characteristics, and few counties. Geographic barriers, like those found in mountainous states, create problems when calculating interregional labor relationships in a similar manner. In addition, estimations suffer from a lack of observations where too few counties exist. As such, smaller states necessitate community-level analyses in order to facilitate modeling.

*Graduate Assistant, The Pennsylvania State University, University Park, PA; Professor, University of New Hampshire, Durham, NH; Assistant Professor, The Pennsylvania State University, University Park, PA; Associate Professor, University of New Hampshire, Durham, NH; and Professor, University of New Hampshire, Durham, NH. Scientific Contribution Number 2021 from the New Hampshire Agricultural Experiment Station. We are grateful for financial support from NHAES Project H 269, the New Hampshire Office of State Planning, and the Northeast Regional Center for Rural Development. We also received helpful imput from Dave Swenson, Tom Johnson, Roy Duddy, the CPAN network, and the anonymous reviewers. Any remaining errors are the responsibility of the authors. 
Other issues involve ideological and structural differences among states and their locales: when considering government policy and finance, it must be observed that regional and local differences in the structure, capacity, and objectives of the government exist. Thus, the need to develop a community-based model applicable to smaller states like those in New England was recognized.

In order to address this particular need, as well as other modeling issues, a variety of regional economists and rural social scientists formulated the structure of an econometric-based fiscal impact model for communities (COMPAS) to be used as a conceptual framework for comparing economic, demographic, and fiscal impacts that result from economic change within each community (Johnson and Scott 1997a). This unified effort was fostered by the development of fiscal impact modeling systems in a number of states over the last several years, beginning with Virginia and followed by others in Iowa, Kansas, Minnesota, Nebraska, Pennsylvania, and Wisconsin, to name a few. This research was extended to New Hampshire through the development of an integrated fiscal impact model specifically designed for New Hampshire communities (FIT-4-NH).

FIT-4-NH (A Fiscal Impact Model for New Hampshire Communities) was created to assist New Hampshire communities in their efforts to understand the impact of changes to the local economy. The model focuses on historical relationships in the local economy, municipal services, and school district services of the state's individual communities. Similar to its predecessors, FIT-4-NH relies on a set of equations that represent sectoral relationships in local communities, examining the relationships between employment, income, and other factors pertaining to local economies. However, it is unique in that its unit of analysis is at the municipal rather than county level, containing data analysis and modeling capabilities for 205 New Hampshire municipalities, and it is among the first designed to capture the specific characteristics of northern New England.

This article begins by summarizing the need for a community-based fiscal impact model in New Hampshire. Then the basic mechanics of FIT-4-NH are discussed, with particular attention given to the specification of the model and problems encountered in transforming its county-level ancestors into a communitybased model. Finally, model validation is considered by testing the results of simulations completed with FIT-4-NH.

\section{NEED FOR A FISCAL IMPACT MODEL IN NEW HAMPSHIRE}

Prior to the 1970s, rural America served as an integral part of the product cycle, mainly by providing businesses with natural resources. The most persistent problem was that as economies and technology progressed, resource-based industries produced more with the aid of fewer employees. During the 1970s and 1980s, small towns were hit hard by slowdowns in both manufacturing and agriculture. This led to the reduction or closure of many natural resource operations, as well as manufacturing branch plant moves or closures. The resulting decline of employment and income had a devastating ripple effect on communities throughout 
rural America. This was illustrated in the 1980 Census (U.S. Department of Commerce 1980), which reported that 485 rural counties exhibited continued and persistent poverty.

In many respects, the current and future state of rural communities has been and will be the result of changes outside of the local area. Yet, regardless of the origins of change, small communities must adjust. These efforts begin with basic economic development planning at the local level, which focuses on creating policies that complement rather than diverge from national economic objectives. Unfortunately, even when rural communities have clearly stated objectives, many still require support and technical assistance from outside sources. This outside expertise can aid in the understanding of the community consequences of policy alternatives or of individual economic development strategies (Johnson and Scott 1997b).

The patterns of growth and decline that typify rural America as a whole apply to the northeastern portion of the country, and particularly to a predominantly rural state like New Hampshire. In the southern and coastal regions of the state, continuing increases in population and housing, as well as other exurban trends, have raised concern as to the effects of growth on municipal budgets. Communities question whether additional tax revenue will adequately cover the costs of increased public service demands. Northern and central New Hampshire communities focus more on the ever-declining forest industry and the growing tourism sector. In these areas, there have been efforts to strengthen the traditional industries by exploring and recruiting a variety of alternative lumber and wood products businesses, yet this has been less successful than efforts to satisfy the demands of both short-term and long-term visitors to the state. As such, communities are not only grappling with increased seasonal demands for public services, but also with growth in seasonal employment and stable or declining full-time employment. In addition, the issue of capacity, the resources and expertise necessary to cope with these increasingly complex problems, remains (Sokolow in Hawley and Mazie 1981). Whatever the predicament, it was clear that New Hampshire municipalities were in need of a tool that would help estimate the fiscal impacts of demographic and labor force-related changes in their localities, without adding to their financial burdens.

\section{MODEL STRUCTURE}

FIT-4-NH is a basic integrated fiscal impact model, derived from community data, to be used for short-run impact analysis at the municipal level by local constituents. Similar to previous models and the COMPAS design, the FIT-4-NH model structure is comprised of three specific components or modules: a community labor market and demographics econometric component, a municipal government econometric component, and a central input-output (I/O) industry production component. Each module was developed to capture explicit measures of economic activity in the local community and the model design allows for 
interaction among the three so that changes in one module will coincide with changes in the others. What follows is a summarization of the steps in the FIT-4$\mathrm{NH}$ model building process, which involved: 1) interpretation of existing relationships into an econometric model; 2) obtaining data; 3) estimation of both the econometric and I/O models; and 4) various other modeling considerations. However, only a general description of the overall modeling process and underlying theory is presented here since the purpose of this article is not to duplicate prior work (Deller and Shields 1998; Shields 1999; Swenson and Eathington 2000), but rather to provide insight as to how the fundamental constructs of that research were adapted and applied to construct a New Hampshire model. In the following paragraphs, each variable included in the modeling system is discussed (the specified equations are given in the Appendix).

\section{The Community Labor Market and Demographics Component}

The community labor market and demographics component was developed to estimate how an employment change will affect the demographic structure in a community. It is centered on the labor market concept and relies heavily on the assumption that exogenous increases in employment are significant factors in economic growth (Johnson and Scott 1997a). Demand is perfectly inelastic at the exogenous level of employment and labor supply is perfectly elastic at the regional wage level. Labor supply is made up of locally employed residents, incommuters, and outcommuters. Therefore, changes in the number employed or the unemployment rate will cause adjustments in the labor market. However, the choice to reside in or commute to a particular locality is based on a decision stemming from the weighing of the costs and benefits of that action. Since quality and quantity variables are representative of those costs and benefits, they must also be considered in the model. As such, the labor force and demographic equations for FIT-4-NH were defined in terms of pertinent quality and quantity variables.

\section{Unemployed, Labor Force, and Commuting}

The number of unemployed individuals in a specific New Hampshire place is hypothesized to be negatively impacted by the education level of the labor force and the opportunity for employment at an acceptable wage rate. Employment availability in each community is represented by area employment and external employment. Area employment is simply the number of individuals employed in a city or town. External employment is a measure of contiguous employment, or the sum of that which exists in the cities and towns that fall within the same labor market as the locality in question. This measurement is similar to the methods used in both the Virginia and Wisconsin models where weighted variables were not available (Keeling 1987; Shields 1999). Unemployment is positively impacted by growth in the labor force where the increase in the number of individuals seeking work exceeds the number of new or existing jobs available. In the same regard, labor force participation is dependent upon and positively 
influenced by the existence of localized gainful employment and the number of individuals of working age in the community's population.

The decision to commute is not only based on the opportunity for employment at a reasonable wage, but it is also derived from additional factors that influence the level of household utility. Therefore, the decision to commute or migrate to one's place of work is arrived at through consideration of a variety of locational attributes. Traditional location theory supports the tendency for individuals to first base their decision on accessibility to acceptable employment (Fujita 1989). People's willingness to travel (time spent) is believed to vary across as well as within states based on the Tiebout (1956) phenomenon. Accordingly, it is hypothesized that increased accessibility in particular will result in higher levels of commuting. Therefore, distance to employment, defined in terms of the mean travel time to work, is included to capture the effects of accessibility on labor flows. The Iowa model (IE/FIMSE) uses a popular distance-decay approach to capture this effect, as well as a means for estimating external employment, in which the physical locations of places and distance to population-weighted midpoints are utilized to produce a more robust measurement (Swenson 1996). However, this method was not applicable to the New Hampshire model because it only works well for states that have relatively uniform county sizes, populations, and no meaningful physical barriers (Swenson 1997).

New Hampshire has many physical barriers in the form of mountains and waterways, and the lack of transportation networks is an impediment to worker mobility as the infrastructure of New Hampshire is underdeveloped in comparison to many U.S. states. Also, population size is not uniform due to significant increases in population size from northern to southern regions of New Hampshire. After investigating alternative methods, it was determined that external employment would best be represented in the New Hampshire model as an estimate of contiguous employment by labor market (the sum of employment in the cities and towns that fall within a labor market, as defined by New Hampshire Employment Security, minus that which exists in the locality in question). This measurement is not identical, but is similar, to the methods used in both the Virginia (Keeling 1987) and Wisconsin (Shields 1999) models.

Housing characteristics, such as availability and cost, have also been shown to weigh heavily in the decision process (Can and Megbolugbe 1997). As such, local median housing costs and the number of local housing units available are included in the general commuting equations. Variables related to environmental quality and housing amenities were also found to be influential, but specific data for these quality measurements are not available at the municipal level (Smith 1996; Benson 1998). However, it is reasonable to assume that such variables influence housing costs and, therefore, their effects are indirectly captured in the model. 


\section{Population and Enrollment}

Population and enrollment are also considered to be functions of the labor force and the socioeconomic conditions that affect the participation rate and the dependency rate (U.S. Department of Health and Human Services 1997). Population is stated to be dependent on the labor force and the total participation rate, which are believed to capture the influence of employment and income, as well as child bearing, on the resident population of a place. The size of the labor force or the existence of a population that is likely to have school-age children varies among communities, as does the rate of participation by women in the workforce. As such, the variables labor force and female participation rate are used to predict the relative presence of children in the community and therefore enrollment expectations. Also included to capture the affordability of raising a family by individuals and the community as a whole are the variables total participation rate and the dependency rate, or the ratio of the nonworking population to the working population. Increases in each would be expected to increase and decrease the number of school-age children, respectively.

\section{Income}

The inclusion of an income variable is important to this model as it drives much of the municipal component. Demand conditions of municipal goods/services are captured by the population, their income, and a vector of other relevant variables that shape needs and expectations. In conjunction, supply of such provisions is in part dependent on the total income capture of the community (Garrett and Leatherman 2000). Realistically, total income is the sum of earnings and nonearnings income (unemployment insurance, dividends, transfer payments, etc.). However, researchers have had little success at modeling nonearnings income (Lev 1989; U.S. Department of Health and Human Services 1997) and, therefore, the treatment of this income varies substantially among models. The New Hampshire model offers a simple treatment of endogenous nonearnings income identical to that used in the Wisconsin model (Shields 1998a, p. 99), where total personal income is a function of local earnings.

\section{The Municipal Government Component}

The municipal government component focuses on how change in income, stemming from change in employment, impacts tax and nontax revenue, as well as service, school district, and operational expenditures. In order to accomplish this, an equilibrium point of the public good at which structural demand and supply intersect must be observed (Deller 1996). From this point of view, the impact on price and output is arrived at by interpreting the location and behavior of the point of equilibrium through the estimation of a set of reduced form equations that consider demand conditions, commuting patterns, quality and quantity, and input conditions. Demand conditions pertain to variables that reflect the tastes and preferences of the local population. Commuting patterns are considered 
separately because they represent a set of demand conditions that are influenced by commuters, and are therefore fundamentally different from local demand factors. Quality and quantity are representative of the output level, and input conditions include the effects of all relevant factors related to the provision of the good, such as price. Expenditure projections are usually made using a baseline assumption of service levels, that is, the assumption of a constant service-level budget (Aronson and Schwartz 1987). As such, no discretionary changes in service levels were built into the model.

Per capita expenditures for ten public services are derived in the New Hampshire empirical model. The decision as to which expenditures should be included in the model, as well as which revenues, was based on the availability of New Hampshire City and Town Financial Reports, which document revenues and expenditures in uniform categories. Municipal services provided include police and fire safety, sanitation, public health and welfare, culture and recreation, roadway, general government, school district, and a variety of other minor provisions that fall into a catchall category (such as contractual services). The determining factors of demand, supply, quantity, quality, and commuting patterns are shared for many of these services, yet the specification of each is dealt with separately in the following paragraphs.

\section{Protective Service}

Area per person is a population density measure to indicate the effects of congestion on the level of police protection demanded. Protective service employment is a proxy for service quality and exhibits a positive relationship to expenditures through employment costs. Per capita income and valuation per capita are indicators for both the ability to pay for service and overall demand for protection (Blomquist, Berger, and Hoehn 1988). Incommuters create an additional need for police protection during the commuting hours. Also, the total participation rate, population size, and the level of crime reflect a direct demand for increases in the quality and quantity of police protection.

Similar to the relationship with police protection, per capita income reflects both the ability to pay for service and the demand for overall property protection services by both businesses and households. Also, the number of individuals employed in protective service per capita is a measure of quality and has a positive relationship with fire expenditures. Therefore, as volunteer firefighters are replaced by professional firefighters, or as more professionals are hired, costs are expected to increase. In addition, growth in the resident and nonresident population, as well as the number of housing units, will lead to increases in fire expenditures.

\section{Sanitation}

The provision of sanitation services is characterized by the inability to vary capacity, so the overall cost structure is a consideration in revenue allocation for 
this expenditure. Thus, revisiting the determinants of initial need for such services and additional need for capital outlays, sanitation expenditures are hypothesized to be positively impacted by per capita income, equalized assessed valuation per capita, debt service, and area. It is also believed to have an inverse relationship on a per capita basis with population in the short run since responses to changes in population will not be met with immediate change in service capabilities. In this time frame, only minor (if any) increases in sanitation expenditures will take place in order to maintain service level (i.e., additional employees), but it is assumed that the growth in population will exceed any growth in expenditures and therefore per capita expenditures for this service will decrease.

\section{Health and Welfare}

The variables that determine the need for public welfare services are typically representative of the public well-being of the city or town. This holds true for the New Hampshire model as public welfare expenditures are specified in terms of variables that typify underemployment and indicate a household's ability to meet the costs of living in a particular place. Also, it should be noted that most New Hampshire municipalities supply localized forms of public welfare services as an alternative or in addition to that which is state or federally mandated. These local services provide immediate response to direct need and do not subscribe to the formula-driven determinants of need that exist for other public welfare providers.

Taking note of the high incidence of poverty in rural New Hampshire and the general scarcity of jobs relative to metropolitan areas, it is evident that problems of worker discouragement, involuntary part-time employment, and the working poor are especially severe in many communities. Yet, it is not enough that rural households are burdened by low income, they are also burdened by limited access to housing in conjunction with that income and scarcity of rental property. It is generally the case that the amount of income available in rural households for housing expenditures is less than that in metro households, yet rural households often pay similar (and at times even greater) costs for less adequate housing (Hawley and Mazie 1981; Long 1988). In many instances the solution lies in the purchase of mobile homes, which is apparent in the high mobile home to singlefamily and multi-unit housing ratio in most New Hampshire communities (SOICC 1997). These relationships are believed to hold significant weight as factors of demand and supply of public welfare services. Therefore, the inclusion of several interrelated variables was deemed necessary in order to capture the uniqueness of this rural situation. These include population, per capita income, average weekly wages, total participation rate, and local median housing costs. Out of all five variables, per capita income is the only one that negatively influences this expenditure.

Municipalities play a different role in health care provision within the community than the county or state governments, which are often influential in 
terms of county hospitals. Although community-supported hospitals do exist in some cases, the scope of health care expenditures at the municipal level in New Hampshire is more often characterized by support services to defray the cost of health care to individual town residents. As such, the level of this expenditure is need based. Accordingly, the variables that determine individual need also establish the amount expended. It is hypothesized that the resident population in conjunction with per capita income will negatively impact the need for such services. The variables married families with children and total participation rate are included because the need for health care support is often attributed to inadequate insurance coverage as a result of the high cost of family coverage and the lack of opportunity to obtain health insurance through employment (U.S. Department of Health and Human Services 1997). Incommuters and outcommuters per capita also have significant impacts on health care expenditures. Outcommuters are negatively related to health care expenditures because they represent a portion of the town's labor force that demands health care services outside of the specified locality for large portions of the day. The reverse is believed to be true for incommuters who, during their stay in a particular community, may be in need of health care. This particular relationship is indicative of the need for services themselves (most often provided by the private sector and higher levels of government) rather than support as previously described (alleviating individual cost). However, the municipality does play a role in providing health care services, such as the existence of emergency medical service and ambulances that are supplied by the community. In the case of commuters, emergency services are generally what are demanded and, therefore, the municipality often bears the burden of this type of service provision.

\section{Culture and Recreation}

Once again, per capita income is a measure of both the ability to support and the demand for parks and recreation services and facilities, as demand for services of this kind is hypothesized to increase with community income (Braden and Kolstad 1991). However, it is believed that the less congested the area, the lower the demand for such expenditures. Therefore, area per person is included to capture the effects of the availability of recreational space per person in the community. Married families with children and incommuters per capita are also included in the equation and are hypothesized to have unique positive relationships to parks and recreation expenditures. The role of families with children should be clear; however, the impact of incommuters is less obvious. It is hypothesized that commuters' recreation patterns are derived from awareness of opportunities achieved through their travel-to-work experiences.

\section{Roadways}

Similar to sanitation expenditures, other public works expenditures, like those for the building and maintenance of roadways, are characterized by the 
inability to vary capacity and thus the overall cost. Therefore, the response to alterations in roadway usage is lagged and, as such, short-run per capita expenditures are largely derived from changes in the number of users rather than a change in services provided. Accordingly, decreases in incommuting and outcommuting will correspond with increased and decreased per capita expenditures, respectively. This hypothesized relationship considers the maintenance of current service levels in conjunction with associated operating costs and the ability to defray those costs through various user fees (i.e., tolls). Area serves as a proxy for square miles of roadway, which is a major determinant of maintenance cost as well as the need for future capital outlays. Per capita income is also a proxy for the local ability to pay for service provision.

\section{General Government}

General government expenditure is not related to any particular public service; rather, it is a support component for the entire system. Therefore, the basic determinants of supply and demand for all expenditures apply. Labor force, area employment, and per capita income are all hypothesized to be relevant variables based on their relationship to each independent expenditure. Also, there is an assumption of a constant service level in the short run. Thus, decreases in the labor force, community income, and area employment would result in increased per capita expenditures, but not necessarily increased total expenditures. The crime rate is also delineated as a determining factor because general government expenditures include judicial services and court costs. Therefore, the rate of individuals caught committing crimes will positively impact expenditure on services of that sort.

\section{Education}

Per capita income and valuation per capita reflect both the ability to pay and demand for a particular level of education. It is hypothesized that more affluent communities demand a higher quality of education. The variable married families with children is included because variances in spending levels are often attributed to the types of families that are attracted to a particular place (Swenson 1998). Similarly, the education rate of the current population places specific quality demands on education provisions. Therefore, married families with children and the rate educated are also hypothesized to have a significant positive influence on the quality of education. The number of school age children and the working age population are determinants of quantity demanded, the first exhibiting a positive influence and the latter a negative one.

\section{All Other Expenditures}

The category all other expenditures includes a multitude of items ranging from stationery and gasoline to contractual services (Aronson and Schwartz 1987). It is similar to general government expenditures in which the more common 
determinants of demand and supply are applicable. However, the scope of expenditures included in this category may be expansive and therefore difficult to model. As such, the following variables mutually representing both quantity and quality are deemed appropriate measures: per capita income, labor force, and total participation rate. Per capita income and labor force are assumed to have a negative impact on this per capita expenditure. Total participation rate is a proxy for community need and is expected to have a positive relationship.

The revenue side of the model is significantly more difficult to define, as revenue equations are dependent upon the specific source(s) and accounting structure of the revenue in question. The purchasing power of a community is best measured by income (or some proxy thereof), which is the principal measurement used by local governments to forecast revenues (Aronson and Schwartz 1987), thereby ignoring the political dimension. Therefore, it was concluded that specifying local revenue sources in terms of income, measures of wealth, and factors that influence income and spending is a reasonable approach.

\section{Property Tax}

Local government revenue raised from own sources in New Hampshire consists mainly of property tax revenue. A variety of other tax and nontax revenue sources exist, such as a resident or head tax (similar to per capita tax) and user charges, but they contribute minimally in comparison to property tax (although their contribution is substantially greater for municipal government expenditures than for school district expenditures, e.g., automobile registration fees). Therefore, in this model they are treated as a composite measure rather than independently.

There are several suggested ways in which to close the fiscal impact (municipal) equations (Johnson and Scott 1997a). One is to assume that government expenditures are determined prior to the setting of tax rates designed to make up the difference between those expenditures and other revenue sources (as in the Virginia model). An alternative approach (used in the design of the Missouri model) is to assume that the tax rate remains constant and, therefore, economic changes result in fiscal deficits or surpluses. The first approach applies to New Hampshire since in most of its communities the tax rate is determined last by way of additional revenue needs and political considerations. As such, the property tax rate, and therefore the revenue collected, is ultimately a manifestation of the variables that influence total expenditures, total other revenue sources, and the ability of the locality to produce property-generated revenue (people, personal wealth, and real property value). In light of this process, it was determined that property tax revenue is best specified in terms of the aforementioned variables rather than just as a mere calculation of the tax rate and the tax base, as is the case in most other models.

Property tax is assumed to have a positive relationship with all variables in the equation except for population and total other revenue. It is believed that as population rises, the marginal utility of real property will decrease and that increases in total other revenue will decrease the need for property tax revenue. 


\section{Miscellaneous Revenue}

In this model, miscellaneous tax revenue and funds includes all monies collected by the municipality other than property tax and intergovernmental revenue. It is hypothesized to be a positive function of incommuters per capita and debt service. Incommuters are included because they will not only engage in employment activities, but also in consumption activities during their commute (Keeling 1987). Debt service is representative of funding for capital outlays, such as user charges and revenue bonds. Some may argue that debt service has a more direct impact on property taxes since general taxation is often the appropriate source of such funds (Aronson and Schwartz 1987). However, since property tax is considered last in the stream of revenue sources in most of New Hampshire (as discussed previously), it is assumed that alternative means to variations in millage rates are first employed. Therefore, the impact of debt service is a positive direct impact to miscellaneous tax revenue and funds, and possibly an indirect impact to property tax via induced changes to the tax rate resulting from the difference between total expenditures and total other revenue. Miscellaneous tax revenue and funds are believed to have a negative relationship on per capita income. An example of this relationship is that the inability of one to pay taxes owed, due to lack of appropriate income, may result in the application and collection of interest and penalties by the town.

\section{Intergovernmental}

Modeling intergovernmental revenues often proves to be the most troubling. This is largely due to the fact that aid levels are mainly determined by demand factors derived from political influence and by supply-side factors, which may or may not be responsive to local demand characteristics, but are often tied to local expenditure levels (Keeling 1987). In addition, intergovernmental aid and grants often serve as rather significant revenue sources for local government. Data has shown that local governments are particularly dependent on intergovernmental assistance from state government and that these transfers make up about onethird of total local revenue (Aronson and Schwartz 1987), therefore, accurate estimation is essential. Luckily, modeling this revenue for New Hampshire was made simpler by two factors: 1) the influence of state and federal government funding in New Hampshire is not so drastic, as financial assistance remains relatively low compared to other states (approximately one-fifth the per capita national average according to the U.S. Department of Commerce 2000); and 2) consistent variables were found in allocation formulas applied to New Hampshire communities, including those representing local wealth and population density. Therefore, intergovernmental aid is specified in terms of population, area, and per capita income, with the assumption that the greater the population to area and the lower the individual wealth, the greater the chance of receiving aid. 


\section{Data Collection and Town Selection}

Prior to parameter estimation, the process of collecting and organizing data into a useable electronic data file needed to be undertaken. The relatively small size of the state of New Hampshire, which contains only ten counties (lacking degrees of freedom for econometric analysis), required that individual community rather than the traditional county-level data be used in the analysis. This was acceptable since a community-based model was the goal. However, data collection at this level is challenging and has the potential to raise many issues related to the econometric method due to its heavy reliance on the data. For instance, the existence and stability of statistics provided by others directly impacts the quality of the parameter estimates and, therefore, the accuracy of the model itself. This issue in particular was faced with FIT-4-NH, as in the data collection process it was discovered that many calculation errors existed in the municipal revenue and expenditure accounts that had been reported to the New Hampshire Department of Revenue Administration.

Other problems included the scope and regularity of data collection at the local level, which is generally inconsistent and less than adequate across communities in non-Census years. This problem is fostered by the fact that rural communities do not have the resources for data collection and maintenance that are available at the county level and, suffice it to say, the need for such data the municipal level is often outweighed by the cost. As such, the most recent comprehensive database found for New Hampshire communities was that stemming from the 1990 Census. This meant that the accuracy of the model must once again be compromised, this time by relatively dated statistics, and that the data would need to be updated and parameter coefficients recalculated as soon as more recent numbers became available (from the 2000 Census).

At this juncture, the effects of variations in town size, revenue and expenditure levels, and the differences in the socioeconomic relationships of metropolitan and rural areas were also considered. It was deemed appropriate to delete the small number of large cities in New Hampshire whose fiscal characteristics were outside the realm of the average community and whose inclusion in the model would inadvertently skew the results. Therefore, all towns or cities that fell above or below two standard deviations from the population mean of all defined places in New Hampshire were left out of the model. Towns with a population less than 500 were also discarded, bringing the total number of communities in the model down to 205 from an original 234 .

\section{Estimation Procedures}

Initially, all equations in the FIT-4-NH model were estimated as a system using the three stage least squares method strongly recommended by experts in the field. However, efforts to estimate the rich set of revenue and expenditure equations often fail to produce stable model coefficients (Swenson 1997). Opting 
to maintain the analytical detail of the model rather than compromising it by limiting the revenue and expenditure items in order to achieve stability, alternative methods of estimation were chosen (Wooldridge 1996). This approach allowed for the establishment of an applicable model that can be improved upon in the future.

Stable coefficients were obtained by estimating the labor force and demographic equations as a simultaneous system using three stage least squares. The expenditure equations do not consist of any jointly determined variables, yet they do share some exogenous variables (factors of demand). Therefore, seemingly unrelated regression (SUR) was used for the expenditure equations. Applying SUR to a set of equations in which this relationship does not exist will yield the same results as Ordinary Least Squares regression (OLS), which is what occurred when attempting the same analysis for the revenue equations. As such, OLS was used for the revenue equations, as well as for the income equation.

The empirical results of all equations, which were assumed to be linear and were specified and estimated in the manners previously discussed, were acceptable for the purpose of completing this initial fiscal impact model for New Hampshire. Although equation-by-equation analysis will not be undertaken here, it can be said that each individual econometric model was found to be significant as a whole (significant F-statistic) and that no severe problems with either multicollinearity or heteroskedasticity were encountered. In addition, overall, the predicted theoretical outcomes were supported by the data.

\section{Other Considerations}

All things considered, it is appropriate to now contemplate how the system results affect local decision making in general. The importance of the community labor market and demographic results from a policy perspective surfaces in the inferences that can be made regarding the spatial distribution of local growth and its impact on residential choice. The indication is that new, reasonablepaying jobs may be filled by people currently living either inside or outside of the community (both incommuting and outcommuting are similarly impacted by differences in employment opportunity), who as a result of the new job have the potential to migrate in any direction within the labor market. This undefinable residential movement stemming from job opportunity exacerbates the innate difficulties of public service provision at the local level. It also requires that local officials be aware that substantial amounts of local development benefits may not necessarily accrue to local residents (Shields 1998a), as the opportunity for leakages is plentiful. These issues certainly exist at the county level as well; however, migration patterns related to employment are more easily identifiable where the land area of the region being considered is larger. For example, the desire to work and reside in separate counties is rather limited for most due to consideration of a variety of issues, particularly distance and accessibility. Therefore, it is reasonable to assume that in most cases increased employment opportunity within a county will result in migration to that county. However, pinpointing exactly 
where in that county the individual or family will choose to reside is another matter, which clearly illustrates the difficulties faced by local governments.

All revenue and expenditure equations were estimated in per capita terms in order to insure that no spurious correlations due to size occur (Keeling 1987). Overall, the revenue and expenditure results support the hypothesized relationships that were expected to exist in New Hampshire communities. This tells local policy makers that when making fiscal decisions they should keep in mind that consumers are not concerned with physical units of public goods or their inputs, such as a fixed number of hours of police patrol. Continuing with this example given by Hawley and Mazie (1981), what residents want and are willing to pay for is the smallest probability possible (considering all other service conditions and socioeconomic factors jointly) that members of their household will be affected by crime. As such, theoretically, they are indifferent to the number of hours of labor required to reach this determined marginal level of safety. However, the input requirements for this service level may be substantially different across communities and, consequently, grave differences in per capita costs for equal services may surface. The main reasons for this variance are what are known as service conditions, which need to be included in all local government production functions (Hirsch 1977). For example, in a community where there already exists a lower underlying risk of crime (different service conditions), the municipality is able to achieve a given level of police protection at a lower cost. Therefore, municipal governments need to take into consideration all of the socioeconomic conditions that affect their ability to provide community members with the types and levels of services that they demand.

In addition to service conditions, input costs also vary across localities. These input costs may include differences in labor costs, which are major inputs for all local government services and are highly dependent on the cost of living in a particular place. In rural areas, many inputs are often donated, such as volunteer labor for fire departments. Lacking this financial burden, the fiscal capabilities of the local government may be expanded. However, such dependence may create a crisis in light of growth, whereby volunteer services are not sufficient to maintain the necessary service level, thus creating the need for significant financial inputs on the part of the municipality. As such, it is wise for community officials to anticipate changes to their community and to be aware of its current and future service capacity.

Local officials also need to be aware of their revenue capacity, particularly that concerning property tax. Since expenditures are determined first, the community's ability to pay and resulting tax effort are important considerations and are quite difficult to measure. For instance, at first glance one cannot distinguish between communities whose revenue production is low due to lack of taxable capacity and those whose property tax revenue is low by choice. However, such revenue is not only determined by the existence of a tax base, but also by its characteristics. In other words, the individuals that make up the tax base may be 
financially unable to bear heavy tax burdens or they may simply be unwilling to do so and exhibit this disagreement through political means.

In addition to property tax issues, local officials must have a keen sense of the limitations of other revenue sources. For instance, if they have previously made no efforts at obtaining intergovernmental aid, then unlimited possibilities may exist. Yet, if they have already sought such revenue, then this revenue opportunity may be exhausted. Other revenues, such as user fees for public beaches, may or may not already be in place and if they do exist there may not be an option for increases. Also, instituting such fees may place additional financial burdens on the residents, making it impossible for them to partake in the use of such public services (excludability) and/or these actions may lead to political repercussions. Therefore, it can be said that capacity, in terms of revenue options, as shown to be determined by a variety of community factors, is a vital concern for policy makers and one that necessitates a great deal of awareness within one's community.

\section{The Industry Production Component}

The industry production component was the last component addressed in the completion of FIT-4-NH. Using a standard I/O program (IMPLAN), the production relationships between the local industries were used to predict how the direct changes in demand in one industry induce production demand changes in other local industries. Then, by applying the resulting Type I Multipliers (direct and indirect interindustry effects), estimates of total change in employment and the resulting income brought about by a change in production were ascertained.

In generating the I/O multipliers for New Hampshire, 1994 county data had to be used, as the availability of interindustry data is limited in general and is even more inconsistent at the local level. The difference in the data used for the econometric analysis (1990) and the I/O analysis (1994) limited the ability for true integration of the modules to take place. In order to alleviate this problem, many modelers make the assumption that the technical coefficient matrix $A$ is constant over time, as was done for FIT-4-NH. This is acceptable in the short run and, therefore, data for each component can vary by a reasonable number of years.

\section{Model Construction and Design}

Once all of the analyses were conducted, the construction of the model was undertaken, beginning with the interactive method of the $\mathrm{I} / \mathrm{O}$ and econometric components. The way in which the $1 / O$ and econometric models are combined varies substantially among existing conjoined models. The integration strategy intended for FIT-4-NH was the linking strategy, which is a commonly employed approach; other options include embedding and coupling strategies (Rey 1994). Regardless of the different integration methods and outcomes, the general means for integration is in some way to replace the aggregate production function of the econometric model with the I/O model (estimates on industry output, employment, and value added). In linking models, interaction between the two components takes place only once. A shock is introduced to either the I/O or econometric 
component. The change that takes place in the shocked component is then initiated into the remaining component, generally the econometric one where the dynamic impacts of the shock are determined.

The model itself was built in a Microsoft Excel 97 workbook and is divided into several worksheets that represent the model components and various user needs. Specifically, it is broken down into: 1) a data table; 2) an industry table; 3 ) ten county worksheets; 4) a labor table; 5) a municipal table; and 6) a results table. This design is an adaptation of the Wisconsin model (Shields 1998b). The major design difference between the two models, and other fiscal impact models for that matter, is the incorporation of the county worksheets. In order for FIT-4-NH to be used firsthand by community members, the employment multipliers had to be calculated ahead of time and built into the model so that each town would be able to derive the total changes in employment and income for the county in which they reside. This required that ten sets of multipliers be developed and entered into separate county worksheets, which then needed to be incorporated into the model so that no matter which county was being considered, proper interaction with the rest of the model would take place. The inclusion of the industry table was also aimed at increasing the user-friendliness of the model.

\section{MODEL VALIDATION}

In reviewing the literature and examining the documentation of other models, it was made clear that systematic and rigorous validation of modeling efforts is in most cases lacking. Suggested validation techniques are plentiful, including graphical analysis, analysis of turning points, and quantitative measures of simulation fit (root mean square error, mean simulation error, mean absolute error, etc.). Yet documentation as to the application and success of these methods is indeed a rarity. However, in the literature there is reference to some work that has been done in the validation of models whose basis is time series analysis. One such attempt to adapt these validation methods to fiscal impact models was made with the Virginia model (VIP), which involved the validation of the baseline procedure through Theil's coefficients (Theil 1971). Another effort to validate the accuracy of the model by reproducing the impacts of changes that occurred in the past (an ex post forecasting approach) is referred to as "backcasting." This technique, although seemingly reasonable, is hindered by many things, such as the ability to capture lagged effects and effects of changes in the national economy (nonlocal changes that produce local impacts) and the existence of beforeand-after analyses of specific changes that actually took place to which to compare the modeling results. Ways in which to reconcile these and other issues so that the method may be applied are currently being investigated by modelers in Missouri (Johnson 1999). However, documentation regarding the details of that work is not yet available. Faced with a lack of choices, most modelers validate their models based on the reasonableness of simulations. Therefore, the same method was applied to FIT-4-NH, in which simulations for proposed developments in two New Hampshire towns (Milton and Whitefield) were conducted. 
All statistical and background information for the towns was obtained from publications by the Economic and Labor Market Information Bureau, New Hampshire Employment Security (1990) and the State Occupational Information Coordinating Committee of New Hampshire (1997), along with information transferred from community officials. In both case studies, the interpretation of model results included comparison with economic theory and interviews with local officials (Feeney 1999; Maxwell 1999) who were able to draw on their own knowledge of the area in order to determine the reasonableness of the simulation.

\section{Simulations Summary}

The intent of the model simulations was to address the question as to the plausibility of the impact estimates or, in other words, to determine if the results make sense. For each town considered, the impacts were consistent with theory and with what was expected by community experts. Yet, the extent of the accuracy of those estimates could not be determined for certain. In an attempt to gain insight as to the accuracy of FIT-4-NH estimates, two tests were conducted. The combined findings of the tests suggest that a greater margin of error may exist for larger communities whose fiscal budgets are expansive, but for small communities even slight changes may have relatively significant impacts on the municipality as a whole, making accuracy a less than trivial matter.

\section{TABLE 1}

Comparison of Margin of Error and Margin of Change for Total 1992 Values of Selected Variables in Sample Towns (Actual vs. Estimated)

\begin{tabular}{lcc}
\hline TOWN & $\begin{array}{c}\text { MARGIN OF ERROR } \\
\text { (actual-estimated change)/actual change }\end{array}$ & $\begin{array}{c}\text { MARGIN OF CHANGE } \\
\text { shock/population }\end{array}$ \\
\hline Lisbon & $-324 \%$ & $19 \%$ \\
Hill & $-215 \%$ & $18 \%$ \\
Peterborough & $-205 \%$ & $17 \%$ \\
Newport & $-191 \%$ & $13 \%$ \\
Merrimack & $-154 \%$ & $12 \%$ \\
Hudson & $-132 \%$ & $5 \%$ \\
Hooksett & $-127 \%$ & $4 \%$ \\
Jaffrey & $-113 \%$ & $3 \%$ \\
Exeter & $-109 \%$ & $2 \%$ \\
Ossipee & $0 \%$ & $1 \%$ \\
\hline
\end{tabular}

In the first test, actual 1992 town data were compared with the estimated values for a sampling of fiscal variables (eight) in ten towns. Assuming that 1992 budgets are based largely on changes that occurred in the previous year, 1991 increases in manufacturing employment were used to shock the model and produce 1992 estimates so that comparisons could be made (New Hampshire Employment Security 1992). Upon a cursory examination of the results it would be easy to conclude that FIT-4-NH is far from accurate do to the overwhelming differences between estimated and actual values. Yet, such a straight comparison between the values is flawed since other economic shocks, such as changes in the national economy or in other industrial sectors of the local economy, are likely to 
have taken place and impacted the fiscal budget as well. What this test does provide is insight into the accuracy of the model based on the margin of change or the size of the employment shock in comparison to the size of the population. As summarized in Table 1, it was found that the larger the margin of change, the greater the margin of error. In other words, the more drastic the change to the local economic system, the less accurate the model is at estimating the impacts of that change.

The second test compared the estimated changes in revenues and expenditures for places representing the smallest, largest, and average-sized towns (based on those included in FIT-4-NH) in all ten New Hampshire counties given an employment shock of 75 to the service industry. The results revealed a similar relationship in all counties, which is illustrated in Figure 1, using the sample towns for Belknap County. Center Harbor represents the smallest place, Meredith the average, and Laconia the largest. The related estimated changes to both revenues and expenditures are not proportional to the margin of change, but rather are increasing at an increasing rate. Therefore, the smaller the community in comparison to the change or shock, the greater the fiscal impact.

FIGURE 1

Estimated Revenue Change, Expenditure Change, and Margin of Change for Selected Belknap County Towns Given a 75 Job Employment Shock to the Service Industry

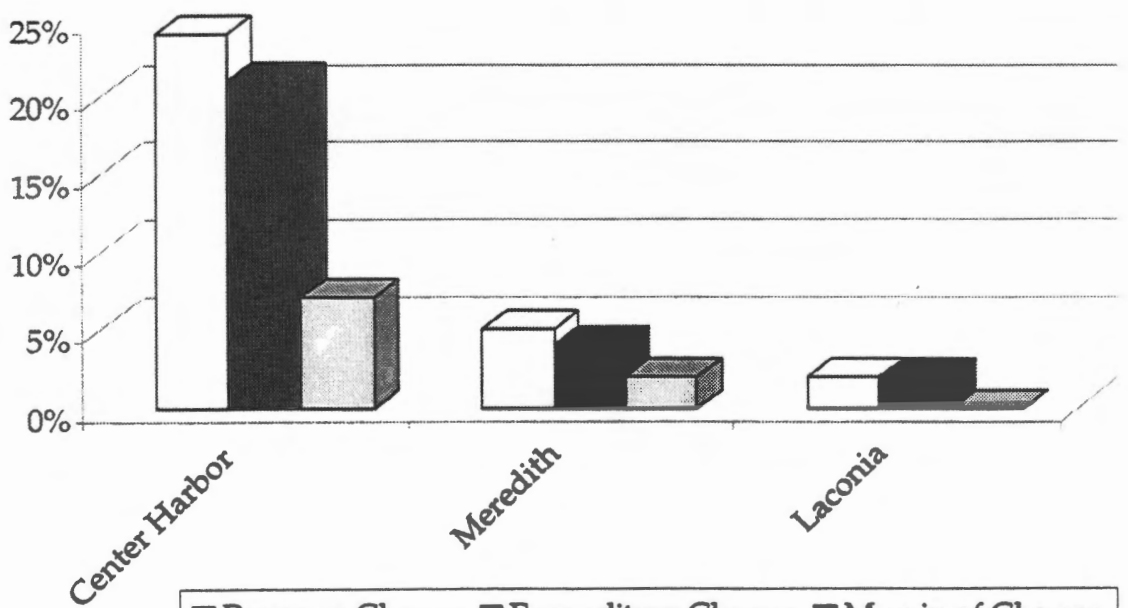

$\square$ Revenue Change Expenditure Change $\square$ Margin of Change

Together, the results of the tests provide useful information in regard to the relative changes that are likely to take place based on both the size of the community and the proposed or actual shock and the accuracy of estimated impacts produced by FIT-4-NH given the ratio of the two. Summarizing those results, it can be said that the smaller the community, the greater the margin of change, the proportionally larger the fiscal impact, and the larger the margin of error. Therefore, even when a seemingly slight change in employment takes place within a 
small community, it could produce relatively large impacts that are difficult to project. This illustrates, in part, the difficulty of constructing an accurate model for smaller places for use at the municipal rather than the county government scale. Regardless, this does not mean that FIT-4-NH is unable to provide useful information, it just means that how the estimates are interpreted is important. It is recommended that estimates provided by FIT-4-NH be used to generate discussion about the possibilities and impacts of a development project in a particular community rather than as a measure of definitive change. This is particularly true in light of capacity issues, as discussed previously.

FIT-4-NH provides insight into the linkages within and among local economies. In this manner, FIT-4-NH can serve as an informative tool when contemplating future development issues in individual New Hampshire communities or in rural towns as a whole, for which current knowledge is decidedly lacking. Some of the linkages uncovered through the Milton and Whitefield simulations, which may or may not have been recognized in other instances, are factors related to migration, commuting patterns, underemployment, and income.

\section{FIGURE 2}

Percentage Change in Revenues and Expenditures in Study Towns

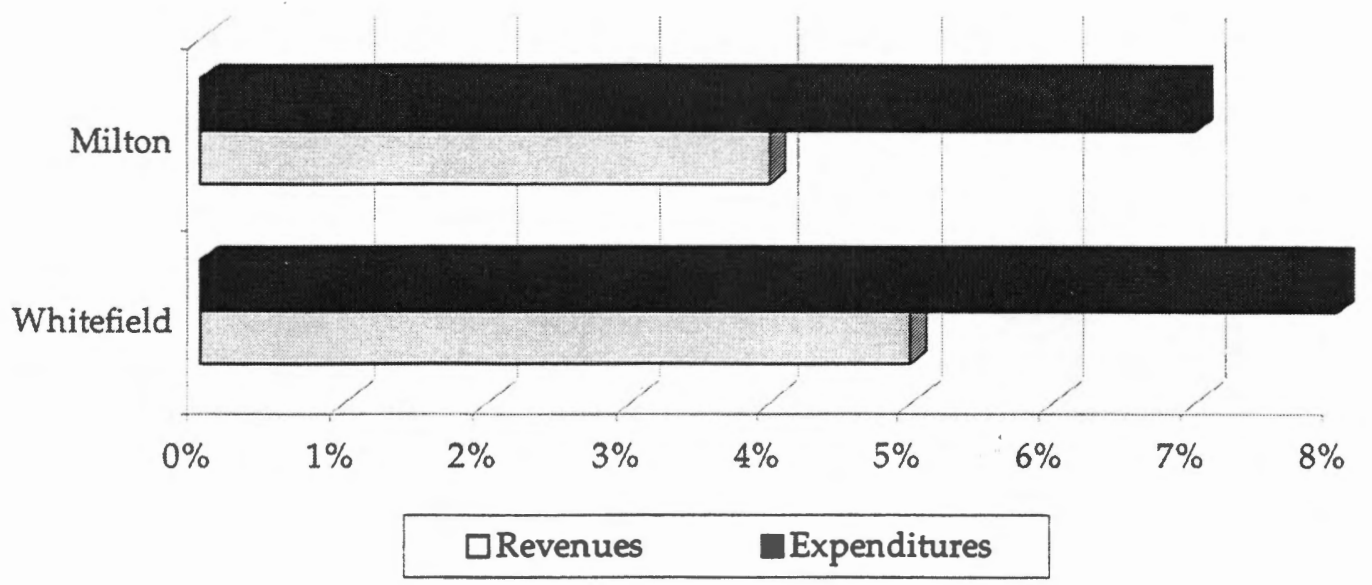

The simulation results support previous findings in both urban and rural studies that substantial changes in in-migration and incommuting will take place when good jobs paying a reasonable wage rate are introduced into a community. Also, similar to the simulation results for the Wisconsin model (Shields 1998a), in instances where commuting takes the place of migration, as was the case in Milton, the impacts to the locality are lessened. This is illustrated in Figure 2, which shows the percentage change in expenditures and revenues for both towns. Whitefield, the simulation community exhibiting the smaller increase in incommuting, experiences the greatest fiscal impact. However, it should be noted that the relative revenue to expenditure change for both towns is practically the same, with 8.2 to 7.3 percent and 5 to 4 percent revenue to expenditure increases for Whitefield and Milton, respectively. Therefore, it could be said that the overall fiscal impact of the 
differing economic changes is comparatively equal, relatively speaking. This finding led to the question of whether or not the relationship holds true for all industries given the same economic shock. As such, a test was run to compare the estimates of FIT-4-NH, where the same change in employment was entered into each industry for a single town, Loudon.

The Loudon results support the simulations for Milton and Whitefield. Although the total change in revenues and expenditures for each industry were estimated to be considerably different, the relative change was found to be quite stable. The reference to the change in incommuters versus resident population was also supported to some degree, as two of the three industries that revealed the greatest relative change in and between revenues and expenditures were also those that had the largest estimated population-to-incommuter change ratio.

The fact that the projected economic impacts of the developments in Whitefield and Milton are at best moderate relative to the size of these towns' economies is not meant to paint a pessimistic view of either scenario or to infer that the effort to increase employment opportunity within the towns is fruitless. On the contrary, it should be considered as support for current and future efforts to improve the economic situation in rural New Hampshire. This sends a clear message to policy makers and others engaging in community and economic development, which is the need for the consideration of all relevant factors when deciding upon various growth and development opportunities.

\section{CONCLUSIONS}

Surely there is much to be learned about the interrelationships existing within rural economies and analysis improvements to be had with improvements in data availability at the local level. However, the intention of this work was to introduce a body of applied research to the State of New Hampshire where it had previously been lacking and, in doing so, provide New Hampshire communities with a cost-effective, reasonably accurate means of measuring fiscal impact, thereby improving the policy decision-making process. This has been accomplished as evidenced by the successful completion of FIT-4-NH.

By way of comparison with the county-level fiscal impact models currently prevailing, community-level modelers clearly must address a number of difficult issues. First, data acquisition at the municipal level is problematic, both in terms of availability and accuracy and in terms of the larger variations in various fiscal variables across towns relative to across counties. Second, while excellent work by previous modelers provides something of a template, the county-level structure must be better adapted to the community level. This involved a line-by-line, variableby-variable examination of other models to construct a similar, but not identical, format to FIT-4-NH's ancestors. Third, the instability of the systems of equations when three stage least squares was applied may well be an artifact of the type of variability of data used in this level of modeling. Finally, the use of county-level I/O multipliers for all towns within a given community may be effectively forcing restrictions on some of the multiplier relationships. 
FIT-4-NH has been well received at various community workshops, and efforts to facilitate its use statewide are underway in cooperation with the New Hampshire Office of State Planning. In addition to its usefulness within New Hampshire communities, this effort has afforded other New England states with a more complete model to build upon, should they choose to pursue a modeling endeavor, because it is designed explicitly for the northeastern region of the country. However, there is much work yet to be done to the New Hampshire model and in community modeling in general that will improve upon the adaptation capabilities of previous models and our abilities to accurately estimate fiscal impacts in general. This effort clearly identified some of the research and development needs pertaining to small rural regions as well as modeling overall. Specific areas of improvement identified for the New Hampshire model include, but are not limited to: 1) data maintenance at the municipal level; 2) proper estimation of the econometric equations as a system; 3 ) dynamic enhancement through the addition of housing and tourism modules; 4) accountability methods for seasonal employment; and 5) evolution of validation procedures.

\section{APPENDIX}

Unemployed (UNEMP) $=f($ area employment $($ AEMP), labor force (LF), average weekly wages (WAGE), external employment (EXEMP), population w/H.S. diploma or higher (RTED))

Labor Force $(\mathrm{LF})=\mathrm{f}($ area employment (AEMP), average weekly wages (WAGE), resident population age $16+($ WKAGE))

Outcommuters $($ OUTCOM $)=f($ area employment $($ AEMP $)$, external employment (EXEMP), average weekly wages (WAGE), local median housing costs (LHOME), \# local housing units (LUNIT), mean travel time to work (DISEMP))

Incommuters $(\mathrm{INCOM})=\mathrm{f}$ (area employment $(\mathrm{AEMP})$, external employment (EXEMP), average weekly wages (WAGE), local median housing costs LHOME), \# local housing units (LUNIT), mean travel time to work (DISEMP))

Population $(\mathrm{POP})=\mathrm{f}($ labor force $(\mathrm{LF})$, total participation rate $(\mathrm{TPRT}))$

School Age Children $(S C A G E)=f($ labor force $(\mathrm{LF})$, female participation rate (FPRT), total participation rate (TPRT), dependency rate (DEPRT))

Total Income $($ TINC $)=f($ total earnings $($ TEARN $))$ 
Police Expenditures Per Capita (POL) $=\mathrm{f}$ (per capita income (INC), incommuters per capita (CINCOM), equalized assessed valuation per capita (VALC), total participation rate (TPRT), crime rate (CRIME), population (POP), protective service employment (PROSV), area per person (APER))

Fire Expenditures Per Capita $($ FIRE $)=f($ per capita income $(I N C)$, incommuters per capita (CINCOM), population ( $\mathrm{POP})$, protective service employment (PROSV), number local housing units (LUNTT))

Sanitation Expenditures Per Capita (SAN) $=\mathrm{f}$ (per capita income (INC), equalized assessed valuation per capita (VALC), debt service expenditures per capita (DEBSV), total local land area (AREA), population (POP))

Public Welfare Expenditures Per Capita (WEL) = $\mathrm{f}$ (per capita income (INC), population (POP), average weekly wages (WAGE), total participation rate (TPRT), local median housing costs (LHOME))

Health Care Expenditures Per Capita (HEALTH) $=\mathrm{f}$ (per capita income (INC), population (POP), incommuters per capita (CINCOM), outcommuters per capita (COUTCOM), married families with children (MFWC), total participation rate (TPRT))

Culture \& Recreation Expenditures Per Capita $(C R E C)=f($ per capita income (INC), area per person (APER), incommuters per capita (CINCOM), married families with children (MFWC))

Roadway Expenditures Per Capita (RDWY) = f(incommuters per capita (CINCOM), outcommuters per capita (COUTCOM), total local land area (AREA), per capita income (INC))

General Government Expenditures Per Capita (GGOV) $=f($ labor force (LF), area employment (AEMP), crime rate (CRIME), per capita income (INC), valuation per capita (VALC))

School District Expenditure Per Capita (SCDIS) $=\mathrm{f}($ per capita income (INC), equalized assessed valuation per capita (VALC), married families with children (MFWC), \# school age children (SCAGE), rate of population w/H.S. degree or higher (RTED), resident population age 16+ (WKAGE))

All Other Expenditures Per Capita $(\mathrm{AOE})=\mathrm{f}($ per capita income $(\mathrm{INC})$, total participation rate (TPRT), labor force (LF)) 
Property Tax Revenue Per Capita (PROPTX) = f(per capita income (INC), population (POP), equalized assessed valuation per capita (VALC), total other revenue per capita (TOTHR), total expenditures per capita (TOTE))

Miscellaneous Tax Revenue \& Funds Per Capita (MTRF) = f(per capita income (INC), debt service expenditures per capita (DEBSV), incommuters per capita (CINCOM))

Intergovernmental Aid Per Capita (IGOV) = f(per capita income (INC), population (POP), total local land area (AREA))

\section{REFERENCES}

Aronson, R.J., and E. Schwartz. Management Policies in Local Government Finance. Washington, D.C.: The International City Management Association, 1987.

Benson, Earl D., et al. "Pricing Residential Amenities: The Value of a View." Journal of Real Estate Finance and Economics 16 (1) (1998), 55-73.

Blomquist, G., M. Berger, and J. Hoehn. "New Estimates of Quality of Life in Urban Areas." American Economic Review 78 (1) (1988), 89-107.

Braden, J., and C. Kolstad, eds. Measuring the Demand for Environmental Quality. Contributions to Economic Analysis, no. 198. Amsterdam: North-Holland, 1991.

Can, A., and I. Megbolugbe. "Spatial Dependence and House Price Index Construction." Journal of Real Estate Finance and Economics 14 (1-2) (1997), 203-222.

Deller, S.C. "Theoretical Foundations of CE Models." Prepared for presentation at the Community Economic Modeling Conference, Madison, WI, June 9-10, 1996.

Deller, S.C., and M. Shields. "Economic Impact Modeling as a Tool for Community Economic Development." Journal of Regional Analysis and Policy 28 (2) (1998), 76-95.

Feeney, M. Personal communication, Milton Town Offices, Milton, NH, 14 January 1999.

Fujita, M. Urban Economic Theory: Land Use and City Size. Cambridge: Cambridge University Press, 1989.

Garrett, T., and J. Leatherman. "An Introduction to State and Local Public Finance." In Scott Loveridge (ed.) Introduction to Regional Science. Regional Research Institute Web Book, West Virginia University, 2000. Available at http://www.rri.wvu.edu/WebBook/Garrett/chaptersix.htm.

Halstead, J.M., F.L. Leistritz, and T.G. Johnson. "The Role of Fiscal Impact Models In Impact Assessment." Impact Assessment Bulletin 9 (3) (1991), 43-55.

Hawely, A., and S. Mazie. Nonmetropolitan America in Transition. Chapel Hill: The University of North Carolina Press, 1981.

Hirsch, W.Z. "Output and Costs of Local Government Services." Prepared for presentation at the National Conference on Non-Metropolitan Community Services Research, Ohio State University, Columbus, OH, January 21, 1977. 
Johnson, T.G. Telephone conversation, University of New Hampshire, 10 March 1999.

Johnson, T.G., and J.K. Scott. "The Community Policy Analysis System (COMPAS): A Proposed National Network of Econometric Community Impact Models." Prepared for presentation at the Federal Forecasters' Conference, Columbia, MO, September 11, 1997a.

. "The Changing Nature of Rural Communities." Prepared for presentation at the National Public Policy Conference, Charleston, SC, September $18,1997 \mathrm{~b}$.

Keeling, J. The Virginia Impact Projection Model. Blacksburg, VA: Virginia Polytechnic Institute and State University, 1987.

Lev, B. "On the Usefulness of Earnings and Earnings Research: Lessons and Directions from Two Decades of Empirical Research." Journal of Accounting Research 27 (1989), 153-193.

Long, L. Migration and Residential Mobility in the United States. New York: The Russell Sage Foundation, 1988.

Maxwell, L. Personal e-mail, Coos Economic Development Corporation, 9 February 1999.

New Hampshire Employment Security. Economic and Labor Information Bureau. 1990 Cities and Towns Factbook. Concord, NH, 1990.

. New Hampshire Employment and Wages by Cities and Towns 1991. Concord, NH, 1992.

Rey, S. "Integrated Multiregional Modeling for Systems of Small Regions." Ph.D. diss., University of California, Santa Barbara, 1994.

Shields, M. "An Integrated Impact and Simulation Model for Wisconsin Counties." Ph.D. diss., University of Wisconsin-Madison, 1998a.

. Personal communication, The Pennsylvania State University, 26 October $1998 b$.

. "An Overview of the Wisconsin Economic Impact Modeling System." Technical Appendix to papers published in The Review of Regional Studies 29 (2) (1999), 175-196.

Smith, V. Estimating Economic Values for Nature: Methods for Non-Market Valuation. New Horizons in Environmental Economics series. Cheltenham, UK: Edward Elgar, 1996.

State Occupational Information Coordinating Committee of New Hampshire (SOICC). New Hampshire Community Profiles. Concord, NH, 1997.

Swenson, D. "Model Construction: Data Sources and Assembly." Prepared for presentation at the Community Policy Analysis Network Conference, Kansas City, MO, November 6-7, 1997.

"The Iowa Economic/Fiscal Impact Modeling System." Prepared for presentation at the Community Economic Modeling Conference, Madison, WI, June 9-10, 1996.

. Personal e-mail, Iowa State University, 25 February 1998. 
Swenson, D., and L. Eathington. A Manual for Community and Fiscal Impact Modeling Systems: Practical Techniques for Building and Applying Community Level Models. Department of Economics, Iowa State University, 2000. Available at http://www.econ.iastate.edu/research/abstracts/NDN0021.html.

Theil, H. Principles of Econometrics. New York: John Wiley and Sons, 1971.

Tiebout, C. "A Pure Theory of Local Expenditures." Journal of Political Economy 64 (1956), 416-424.

U.S. Department of Commerce. Bureau of the Census. 1980 Census of Population and Housing. Washington, D.C., 1980.

. Bureau of Economic Analysis. "Comprehensive Revision of State Personal Income: Revised for 1969-98, Preliminary Estimates for 1999." June 2000 Survey of Current Business. Washington, D.C., 2000.

U.S. Department of Health and Human Services. Indicators of Welfare Dependence: Annual Report to Congress. Washington, D.C., 1997.

Wooldridge, J. "Estimating Systems of Equations with Different Instruments for Different Equations." Journal of Econometrics 74 (2) (1996), 387-405. 